\title{
Enhancing mechanical properties of thermoplastic polyurethane elastomers with 1,3-trimethylene carbonate, epsilon-caprolactone and L-lactide copolymers via soft segment crystallization
}

\author{
S. S. Liow ${ }^{1 *}$, V. T. Lipik ${ }^{1}$, L. K. Widjaja1 , S. S. Venkatraman ${ }^{1}$, M. J. M. Abadie ${ }^{1,2}$ \\ ${ }^{1}$ School of Materials Science and Engineering, Nanyang Technological University, 50, Nanyang Avenue, Singapore \\ 639798, Singapore \\ ${ }^{2}$ Laboratory of Polymer Science and Advanced Organic Materials, LEMP/MAO, Université Montpellier 2, Place \\ Bataillon, 34095 Montpellier Cedex 05, France
}

Received 11 February 2011; accepted in revised form 13 April 2011

\begin{abstract}
Multiblock thermoplastic polyurethane elastomers based on random and triblock copolymers were synthesized and studied. Dihydroxyl-terminated random copolymers were prepared by ring opening copolymerization of $\varepsilon$-caprolactone $(\mathrm{CL})$ and 1,3-trimethylene carbonate (TMC). The triblock copolymers were synthesized by using these random copolymers as macro-initiator for the L-lactide (L-LA) blocks. These random and triblock copolymers were further reacted with 1,6-hexamethylene diisocyanate (HMDI) and chain extended by 1,4-butanediol (BDO). The polymer structure and chemical composition were characterized by ${ }^{1} \mathrm{H}$ NMR ${ }^{13} \mathrm{C}$ NMR and SEC. Their thermal and mechanical properties were studied by using DSC and Instron microtester. Multiblock polyurethanes based on random PCL-co-PTMC copolymers showed strain recovery improvement with increasing PCL content. However, these polyurethanes were unable to sustain deformation at body temperature due to the melting of PCL crystals and low hard segments content. With the presence of crystallizable PLLA blocks, mechanical properties were improved at body temperature without compromising their good strain recovery.
\end{abstract}

Keywords: biodegradable polymers, thermoplastic polyurethanes, soft segment crystallinity, strain recovery, elastomers

\section{Introduction}

Recently, there has been renewed interest in applying biodegradable thermoplastic elastomers (TPEs) for biomedical implants. TPEs are favored over chemically crosslinked networks because of their remoldability and easy processability. Unlike crosslinked elastomeric networks, TPE demonstrates elastomeric properties due to physical crosslinks that are formed as a result of microphase separation between hard and soft segments. Typically, soft segments can provide elasticity and flexibility while hard segments offer the necessary physical crosslink sites.
Polyurethanes (PU) and poly(urethane urea) (PUU) have been intensively studied for several decades for mainly tissue engineering scaffolds and vascular implants because of their compatibility, elasticity and ease of surface modification. The hard segment in PUs typically contains diisocyanate, and their modification is an accepted way to alter properties of thermoplastic PU and PUU. One can enhance elasticity of PU by using an aliphatic diisocyanate instead of aromatic diisocyanate; and improve tensile strength and Young's modulus by increasing hard segments content [1]. However, increasing the

\footnotetext{
${ }^{*}$ Corresponding author, e-mail: Liow0019@e.ntu.edu.sg

(c) BME-PT
} 
diisocyanate content is not desirable in a biodegradable system because of the potential toxicity concerns regarding the degradation products, although this is still a matter of debate $[2,3]$.

To achieve effective elastomeric properties in thermoplastic PU and PUU, soft segments modification, as an alternative, was investigated intensively. In previous studies, soft segments such as poly $(\varepsilon-$ caprolactone) (PCL) $[4,5]$, the copolymer or blend of PCL and polylactide (PLA) [6, 7], triblock PCLPEG-PCL with poly(ethylene glycol) (PEG) as middle block [8], PCL blended with poly(1,6-hexamethylene carbonate) (PHC) [9], and the copolymer of poly(trimethylene carbonate) and PCL (PTMCco-PCL (50/50)) [10] with optimum composition and high molar mass, have shown high elongation, good flexibility and elasticity.

Very few groups have addressed the effect of soft segment crystallization on polyurethane properties. Skarja [11] has reported that soft segment crystallinity strongly affects the properties of PCL-based polyurethanes. When hard segments are unable to aggregate to act as physical crosslink points, soft segment crystal structure may act as reinforcement filler, results in increased ultimate tensile strength (UTS), initial modulus and strain-at-break. A recent study on PEO-based polyurethanes by Waletzko et al. [12] showed that increased crystallinity of the soft block results in decreased strain-at-break and higher permanent set: the higher crystallinity impeded proper stress transfer to the continuous phase. Highly crystalline regions decreased strainat-break instead of acting as load-bearing reinforcement agents.

The objective of this study was to synthesize biodegradable thermoplastic polyurethane elastomers; a parallel objective was to study the effect of soft segment crystallization on the polyurethane properties. PCL-co-PTMC was chosen as the soft segment of the PU. PTMC homopolymer is a completely amorphous biodegradable polymer that exhibits glass transition temperature at $-20^{\circ} \mathrm{C}$ [13]. As compared to PCL, at molar mass range between 40 $50 \mathrm{kDa}$, PTMC showed 30 times lower tensile strength but twice the elongation at break [14]; however, when copolymerized with other polymer such as PCL, PTMC shows better mechanical characteristics. Asplund et al. [10] has recently showed that LDI-based PUU that using poly (CL-co-TMC) as soft segments achieved higher elongation than PUU that based on poly (CL-co-DLLA).

In this study, we tried to lower the potential toxicity of degradation products by using the lowest amount of diisocyanate. Detailed cytotoxicity studies will be published in a separate article. To replace the role of the diisocyanate hard segments, PCL-coPTMC soft segment was further reacted with L-LA to form A-B-A structure, yielding 'pseudo hard segments' via PLLA crystallization. Kricheldorf and Rost [15] have recently studied a similar system, PLLA-b-(PCL-co-PTMC)-b-PLLA multiblock copolymers synthesized by using bismuth(III) hexanoate as catalyst. However, they focused on the polymerization mechanism studies without emphasizing the relationship between mechanical property and PLLA crystallization.

\section{Materials and methods \\ 2.1. Materials}

1,3-trimethylene carbonate (TMC) (BoehringerIngelheim, Germany), $\varepsilon$-caprolactone monomer (CL) (Alfa Aesar, Singapore), L-lactide (LLA) (Sigma Aldrich, Singapore), 1,6-hexamethylene diisocyanate (HMDI) (Fluka, Singapore) were used without further purification. The initiator, 2, 2-dimethyl 1, 3propanediol (DMP) (Fluka, Singapore) was dried in $37^{\circ} \mathrm{C}$ vacuum oven for $24 \mathrm{~h}$ to remove moisture before synthesis. The catalyst, tin (II) 2-ethylhexanoate $\left(\mathrm{SnOct}_{2}\right)$ (Sigma Aldrich, Singapore) and the chain extender, 1,4-butanediol (BDO) (Alfa Aesar, Singapore) were dried over molecular sieves (4 $\AA$ ). Solvents including methylene chloride, hexane and anhydrous toluene were of analytical grade, and used as received.

\subsection{Polyurethane synthesis}

The synthetic approach of the multiblock polyurethanes studied in this work is based on combination of three reaction steps in one pot, as shown in Figure 1 . The first step was to randomly copolymerize $\mathrm{CL}$ and TMC by ring opening co-polymerization with controlled CL/TMC molar ratio $(15 / 85,25 / 75$, $50 / 50,75 / 25$ and 85/15) and target $M_{\mathrm{n}}$ of $5000 \mathrm{Da}$. The following process illustrates the general procedure used to make $20 \mathrm{~g}$ of PCL/PTMC-based polyurethane (15/85) (MP1 in Table 1). 17.5 grams of TMC, $0.436 \mathrm{~g}$ of initiator, $133.3 \mathrm{ml}$ of anhydrous toluene, $3.42 \mathrm{~g}$ of $\mathrm{CL}$ monomer and $0.21 \mathrm{~g}$ of 


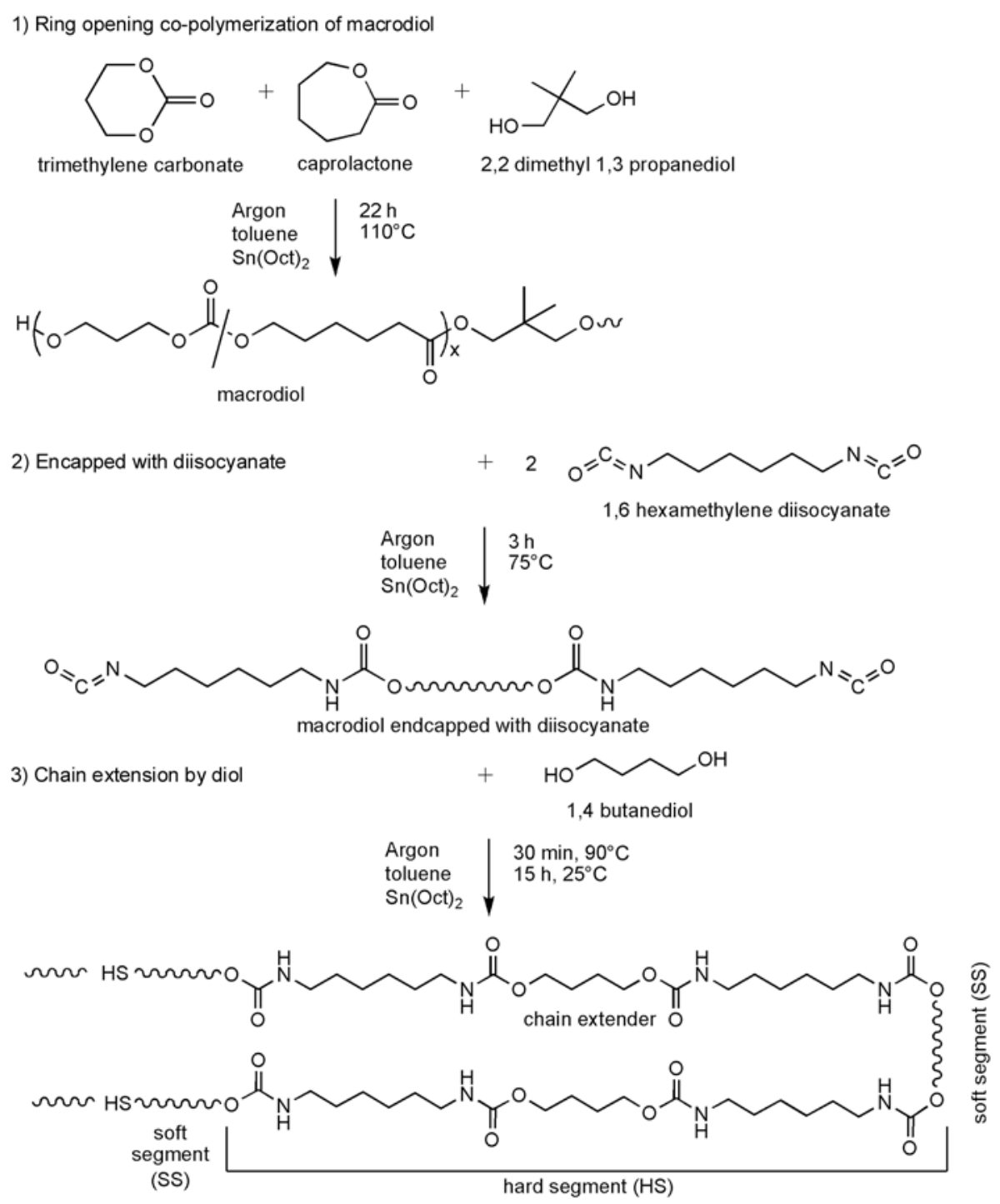

Figure 1. 3-step synthesis of multiblock polyurethanes based on PCL-co-PTMC

Table 1. Composition of soft segments and molar mass of (PCL-co-PTMC) multiblock polyurethanes

\begin{tabular}{|c|c|c|c|}
\hline Multiblock PU (MP) & $\begin{array}{c}\mathbf{C L} / \mathbf{T M C} \\
\text { [mol\% }^{*}\end{array}$ & $\begin{array}{c}\mathbf{M}_{\mathbf{w}} \\
{[\mathbf{D a}]^{\mathbf{a}}}\end{array}$ & $\mathbf{M}_{\mathbf{w}} / \mathbf{M}_{\mathbf{n}}$ \\
\hline MP1 & $15 / 85$ & 57100 & 1.60 \\
\hline MP2 & $25 / 75$ & 59300 & 1.62 \\
\hline MP3 & $50 / 50$ & 58700 & 1.63 \\
\hline MP4 & $75 / 25$ & 69800 & 1.75 \\
\hline MP5 & $85 / 15$ & 78700 & 1.83 \\
\hline
\end{tabular}

MP $=$ Multiblock Polyurethane

*Theoretical values

aDetermined from SEC which was calibrated from polystyrene standards, chloroform as mobile phase

SnOct $_{2}$ ( $1 \mathrm{wt} \%$ of monomer weight) were added into a $250 \mathrm{ml}$ round bottom reaction flask heated to $110^{\circ} \mathrm{C}$ for 22 hours under argon protection and continuous stirring. DMP was employed as initiator because $-\mathrm{CH}_{3}$ showing distinctive peak at $0.95 \mathrm{ppm}$ in ${ }^{1} \mathrm{H}$ NMR spectrum, allows accurate calculations of molar compositions and $M_{\mathrm{n}}$.

In the second step, in the same flask, the resulting PCL-co-PTMC copolymer terminated by two reactive $-\mathrm{OH}$ groups was subjected to polycondensation reaction with 2-fold excess of hexamethylene diisocyanate (HMDI) $(1.39 \mathrm{~g})$ at $75^{\circ} \mathrm{C}$ for 3 hours, to yield diisocyanate terminated prepolymer. The third step was based on the addition of BDO $(0.37 \mathrm{~g})$ in a chain extension reaction, where the mixture temperature was raised to $90^{\circ} \mathrm{C}$ for 30 minutes under vigorous stirring $(>1000 \mathrm{rpm})$. The mixture was then cooled down to room temperature while the chain linking reaction was continued for another 15 hours, under constant stirring. The resulted product was purified by precipitation in cold methanol. The (PCL-co-PTMC): HMDI: BDO molar ratio was set 
to $1: 2.02: 1$. In this way multiblock polyurethanes were prepared with variation in soft segments composition. Hard segment content (wt \%) was calculated by $(\mathrm{g}$ BDO $+\mathrm{g}$ HMDI $) /(\mathrm{g}$ BDO $+\mathrm{g}$ HMDI + $\mathrm{g}$ soft segments). Each polyurethane contains $8 \mathrm{wt} \%$ of hard segments. MP1 ${ }^{1} \mathrm{H}$ NMR $(400 \mathrm{MHz}$, $\left.\mathrm{CDCl}_{3}\right): \delta 4.77,4.41,4.23,4.16,4.12,4.05,3.95$, $3.88,3.66,3.14,2.31,2.04,1.66,1.48,1.40,1.32$, 0.99 .

In the second series, multiblock polyurethanes (MP6-8) were prepared from A-B-A triblock copolymers, with variation of theoretical block ' $\mathrm{A}$ ' length $(1000,2500$, and $5000 \mathrm{Da})$. ROP of L-lactide (block ' $A$ ') was performed in the solution of PCLco-PTMC random copolymer (block ' $\mathrm{B}$ '), when the first step was completed. It was initiated by both hydroxyl-ends of block 'B', at the presence of the catalyst from the first step. Steps two and three were repeated as described previously. MP6 ${ }^{1} \mathrm{H}$ NMR $\left(500 \mathrm{MHz}, \mathrm{CDCl}_{3}\right): \delta 5.15,4.23,4.16,4.12,4.05$, $3.94,3.87,3.66,3.15,2.30,2.04,1.65,1.58,1.51$, $1.37,0.95$.

\subsection{Measurements}

Molar mass of MP1-4 were determined by using Size Exclusion Chromatography (SEC) (Shimadzu LC-20AD prominence liquid chromatograph system equipped with three PLgel mixed-c columns in series and a Shimadzu RID-10A refractive index detector) (Kyoto, Japan). Monodisperse polystyrene standards were used for calibration. Measurements were made at $55^{\circ} \mathrm{C}$ with chloroform as eluent flowing at $1 \mathrm{ml} / \mathrm{min}$. Samples were dissolved in chloroform $(3 \mathrm{mg} / \mathrm{ml})$ and $50 \mu 1$ was injected. Besides, molar mass of MP6- 8 were examined by using SEC system consisted of a Waters 510 HPLC pump, a Waters 410 differential refractometer detector (Milford, MA, USA) with tetrahydrofuran (THF) as mobile phase flowing at $1 \mathrm{ml} / \mathrm{min}$. Samples were dissolved in THF $(10 \mathrm{mg} / \mathrm{ml})$ and $20 \mu \mathrm{l}$ was injected. Measurements were made at room temperature.

Both ${ }^{1} \mathrm{H}$ NMR and ${ }^{13} \mathrm{C}$ NMR measurements were recorded in $\mathrm{CDCl}_{3}$ on a Bruker $400 \mathrm{MHz}$ (Bruker, Fällanden, Switzerland) or Varian VNMRS $500 \mathrm{MHz}$ Spectrometer(Palo Alto, CA, USA). ${ }^{1} \mathrm{H}$ NMR signals were assigned according to several articles [13, 16-18] and ChemNMR ${ }^{1} \mathrm{H}$ estimation from ChemDraw. ${ }^{13} \mathrm{C}$ NMR spectroscopy was used to characterize the sequences of the triblock copolymer. From the dyads splitting of the ${ }^{13} \mathrm{C}$ NMR carbonyl signals of CL, TMC and LLA, the average block lengths of CL, TMC and LLA were calculated. Average block length of CL according to Equation (1) [16]:

$\bar{L}_{\mathrm{CL}}=\frac{I_{\mathrm{CL}-\mathrm{CL}}}{I_{\mathrm{CL}-\mathrm{TMC}}}+1$

where $I_{\mathrm{CL}-\mathrm{CL}}$ is the signal intensity of the CL-CL dyad (signal a in Figure 2) and $I_{\mathrm{CL}-\mathrm{TMC}}$ is from CL-TMC dyad (signal $b$ in Figure 2). Similar equation applied to TMC and LLA calculations.

Glass and melt transition temperatures were determined by Differential Scanning Calorimetry (DSC) (TA Instruments Q10-0095) (New Castle, DE, USA), under constant nitrogen flow. To ensure a consistent thermal history, samples $(5 \mathrm{mg})$ were subjected to cool-heat-cool-heat treatment from -90 to $200^{\circ} \mathrm{C}$ with heating rate of $10^{\circ} \mathrm{C} / \mathrm{min}$ and cooling rate of $20^{\circ} \mathrm{C} / \mathrm{min}$. The second heating data were analyzed. Typically, $2^{\text {nd }}$ heating data are preferred for polymers rather than first heating, in order to wipe out the effects of polymer processing on the results. The degree of crystallinity $\left(X_{\mathrm{c}}\right)$ was calculated according to Equation (2):

$X_{\mathrm{c}}=\frac{\Delta H_{\mathrm{f}}}{w \cdot \Delta H_{\mathrm{f}}^{0}}$

where $\Delta H_{\mathrm{f}}$ is the heat of fusion of the sample, $\Delta H_{\mathrm{f}}^{0}$ is the heat of fusion of $100 \%$ crystalline PCL or PLLA and $w$ is the weight fraction of CL or L-LA in the feed. For PCL and PLLA, the value of $\Delta H_{\mathrm{f}}^{0}$ used for the calculations was $139.5 \mathrm{~J} / \mathrm{g}$ [19] and $93 \mathrm{~J} / \mathrm{g}$ [20] respectively.

The stress-strain measurement was performed on Instron microtester 5848 (Norwood, MA, USA) equipped with $50 \mathrm{~N}$ load cell, at both room and body temperature $\left(25\right.$ and $\left.37^{\circ} \mathrm{C}\right)$. The polymer films were prepared by solution casting, methylene chloride $(15 \% \mathrm{w} / \mathrm{v})$ as solvent, in a Teflon dish. After drying in $37^{\circ} \mathrm{C}$ vacuum oven for 1 week, the films were punched into standard dumbbell shape (according to ASTM D 638 - 08, type V sample with thickness $<4 \mathrm{~mm}$ ) by using Schmidt press. Specimens were pulled at $10 \mathrm{~mm} / \mathrm{min}$ in a temperature-controlled chamber. Testing result was discarded if the failure or necking occurred beyond gage length region.

Under the same operating condition, the cyclic tensile test was carried out. The sample was loaded and 


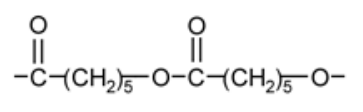

a

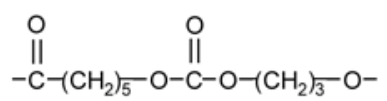

w

a

b

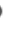
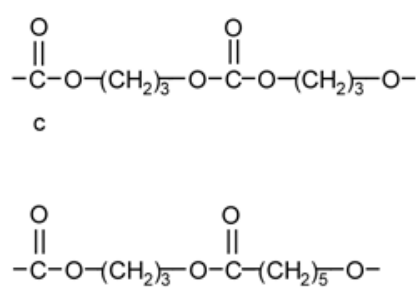

d

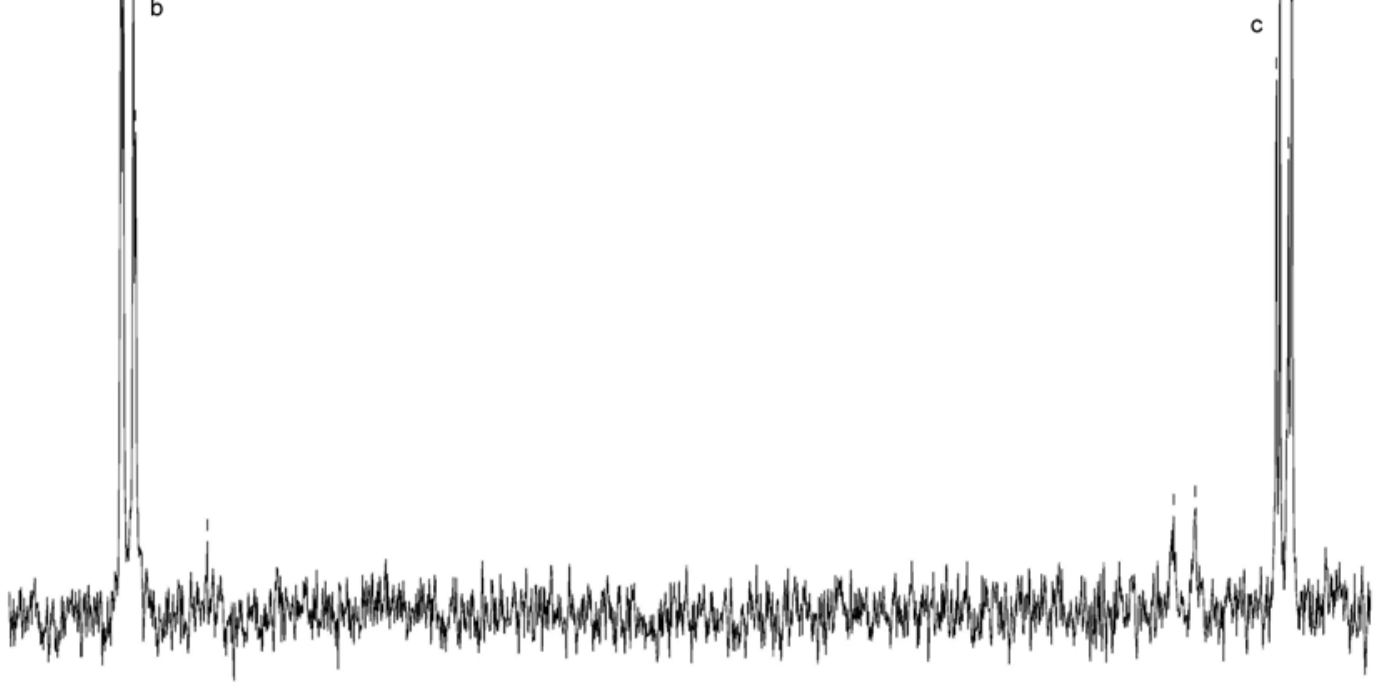

$\begin{array}{lllllllllllllllllllll}174 & 173 & 172 & 171 & 170 & 169 & 168 & 167 & 166 & 165 & 164 & 163 & 162 & 161 & 160 & 159 & 158 & 157 & 156 & 155 & \mathrm{ppm}\end{array}$

Figure 2. $101 \mathrm{MHz}{ }^{13} \mathrm{C}$ NMR spectrum (carbonyl region) of $\mathrm{MP} 3$ in $\mathrm{CDCl}_{3}$

unloaded with $100 \%$ of the initial gage length per minute to $100 \%$ strain, for 3 cycles, or to $100-200$ $300 \%$ strain. The recovered strain $\left(\varepsilon_{\mathrm{R}}\right)$ was calculated as $100 \%$ strain minus permanent set. The permanent set of $100 \%$ strain was determined after a time of recovery (unloading) for 1 minute. For 200 and $300 \%$ strain, the recovery time was $2-4$ minutes.

\section{Results and discussion}

\subsection{Polyurethanes synthesis and characterization}

(PCL-co-PTMC) polyurethanes

Multiblock polyurethanes, with various CL/TMC molar ratios, were synthesized by controlled ring opening co-polymerization (ROP) followed by polycondensation with HMDI and BDO. Targeted soft segment molar mass was achieved by controlling the total monomer/initiator ratio [21-23]. The mechanism of the cyclic esters ROP at the presence of $\mathrm{Sn}(\mathrm{Oct})_{2}$ as catalyst was proposed in several studies $[24,25]$. Table 1 showed the soft segment content and molar mass. The CL/TMC ratio was varied systematically to study PCL crystallinity on mechanical properties, while the hard segment content was fixed as low as $8 \mathrm{wt} \%$.

[PLLA-b-(PCL-co-PTMC)-b-PLLA] polyurethanes In the second series, multiblock polyurethanes were prepared from A-B-A triblock copolymers, which contained PCL-co-PTMC (50/50) as 'B' block, equivalent to soft segments of MP3 in Table 1, and PLLA as 'A' blocks. PLLA block length was controlled by total L-LA monomer/block 'B' macrodiol molar ratio. Table 2 showed the composition and molar mass of the second series. The hard segment content was fixed at $8 \mathrm{wt} \%$.

\subsection{Structural characterization (PCL-co-PTMC) polyurethanes}

NMR measurement in Table 3 showed the details of the soft segments molar mass, degree of polymerization of each segment with respect to one unit of initiator and average segment length. The random- 
Table 2. 'A' block theoretical chain length and molar mass of [PLLA-b-(PCL-co-PTMC)-b-PLLA] multiblock polyurethanes

\begin{tabular}{|c|c|c|c|}
\hline Multiblock PU (MP) & $\begin{array}{c}\text { 'A' block } \mathbf{M}_{\mathbf{n}} \\
\text { [Da] }^{\text {" }}\end{array}$ & $\begin{array}{c}\mathbf{M}_{\mathbf{w}} \\
{[\mathbf{D a}]^{\mathbf{a}}}\end{array}$ & $\mathbf{M}_{\mathbf{w}} / \mathbf{M}_{\mathbf{n}}$ \\
\hline MP6 & 1000 & 64400 & 1.78 \\
\hline MP7 & 2500 & 80200 & 1.77 \\
\hline MP8 & 5000 & 86900 & 1.77 \\
\hline
\end{tabular}

${ }^{*}$ Theoretical values

aDetermined from SEC which was calibrated from polystyrene standards, THF as mobile phase

ness of PCL-co-PTMC soft segments was examined from ${ }^{13} \mathrm{C}$ NMR spectrum of carbonyl region in Figure 2. Average segment lengths were characterized by dyad splitting at 173.4 and $154 \mathrm{ppm}$, which corresponded to CL and TMC segments, respectively $[13,16]$. From Figure 2 and Table 3, as expected, PCL-co-PTMC soft segments were completely and randomly copolymerized.

\section{[PLLA-b-(PCL-co-PTMC)-b-PLLA] polyurethanes} Table 4 showed NMR data of purified triblockbased polyurethanes, including the calculated molar mass of block ' $A$ ' and 'B', degree of polymerization of each segment with respect to 1 unit of initiator, PLLA conversion and average segment length. The completion of the synthesis was examined from ${ }^{1} \mathrm{H}$ NMR spectrum. In Figure 3, ${ }^{1} \mathrm{H}$ NMR signals were assigned: $-\mathrm{CH}_{3}$ signal from initiator $(a),-\mathrm{CH}_{2}$ signals from $\mathrm{CL}(d)$, TMC $(j)$ and $\mathrm{CH}$ signal from L-
LA $(l)$. The formation of urethane groups was indicated by $-\mathrm{CH}_{2}$ from HMDI $(p)$. The blockiness of PLLA blocks and the randomness of PCL-co-PTMC were analyzed from the carbonyl region of the ${ }^{13} \mathrm{C}$ NMR spectrum in Figure 4. Strong lactide signal (e) at $169.5 \mathrm{ppm}$ represented the blocky polylactide structures with the absence of significant transesterification. In addition, the random sequence of CL and TMC segments agreed with MP3 in Figure 2.

\subsection{Thermal properties}

Microstructure of multiblock polyurethanes was studied by using DSC measurement. Generally, soft and hard segment crystallization, and the degree of phase separation can be estimated from thermal transitions such as glass transition temperature, melting temperature, and crystallization temperature. The polyurethane films for mechanical property study and the precipitated macrodiols were used in the thermal characterization.

\section{(PCL-co-PTMC) polyurethanes}

The second heating data were presented in Table 5 , Figure 5 (macrodiols) and Figure 6 (multiblock polyurethanes). All polyurethanes in this study showed $T_{\mathrm{g}}$ below room temperature, indicating rubber-like amorphous structure. MP1-5 showed $T_{\mathrm{g}}$ close to $T_{\mathrm{g}}$ of their corresponding macrodiols SS1-5. The shift

Table 3. NMR measurement of (PCL-co-PTMC) multiblock polyurethanes

\begin{tabular}{|c|c|c|c|c|c|}
\hline Multiblock PU (MP) & $\operatorname{SS~M}_{n}[D a]^{a}$ & CL/TMC/DMP in feed ${ }^{*}$ & CL/TMC/DMP found ${ }^{\mathrm{a}}$ & $\mathbf{L}_{\mathbf{C L}}{ }^{b}$ & $\mathbf{L}_{\text {TMC }}{ }^{b}$ \\
\hline MP1 & 5400 & $7: 41: 1$ & $8: 44: 1$ & 4.5 & 6.4 \\
\hline MP2 & 5200 & $12: 35: 1$ & $13: 36: 1$ & 2.7 & 4.3 \\
\hline MP3 & 5000 & $23: 23: 1$ & $23: 23: 1$ & 2.4 & 2.5 \\
\hline MP4 & 4600 & $34: 11: 1$ & $30: 10: 1$ & 4.8 & 2.4 \\
\hline MP5 & 4600 & $38: 7: 1$ & $33: 6: 1$ & 6.7 & 2.4 \\
\hline
\end{tabular}

${ }^{*}$ Theoretical values

${ }^{\mathrm{a} C a l c u l a t e d}$ from ${ }^{1} \mathrm{H}$ NMR peak integration of peak $\mathrm{a}, \mathrm{d}$ and $\mathrm{j}$

${ }^{\mathrm{b} C a l c u l a t e d}$ from ${ }^{13} \mathrm{C}$ NMR spectra, using Equation (1)

$\mathrm{DMP}=2,2$ dimethyl 1,3 propanediol, the initiator of the PCL-co-PTMC random copolymers

$\mathrm{SS}=$ Soft segments

Table 4. NMR measurement of [PLLA-b-(PCL-co-PTMC)-b-PLLA] multiblock polyurethanes

\begin{tabular}{|c|c|c|c|c|c|c|c|c|}
\hline $\begin{array}{l}\text { Multiblock } \\
\text { PU (MP) }\end{array}$ & $\begin{array}{l}{ }^{\prime} \mathbf{B}{ }^{\prime} \mathbf{M}_{n} \\
{[D a]^{a}}\end{array}$ & $\begin{array}{l}{ }^{6} \mathbf{A}^{\prime} \mathbf{M}_{\mathbf{n}} \\
{[\mathbf{D a}]^{\mathrm{a}}}\end{array}$ & $\begin{array}{c}\text { CL/TMC/LLA/DMP } \\
\text { in feed }^{*}\end{array}$ & $\begin{array}{c}\text { CL/TMC/LLA/DMP } \\
\text { found }^{\mathrm{a}}\end{array}$ & $\begin{array}{c}\text { PLLA } \\
\text { conversion }^{\text {a\# }}\end{array}$ & $\mathbf{L}_{\mathbf{C L}} \mathbf{b}^{\mathbf{b}}$ & $\mathbf{L}_{T M C}{ }^{b}$ & $\mathbf{L}_{\text {LLA }}{ }^{b}$ \\
\hline MP6 & 4900 & 900 & $23: 23: 13: 1$ & $22: 23: 12: 1$ & $92 \%$ & 2.6 & 2.5 & 7.2 \\
\hline MP7 & 4700 & 2100 & $23: 23: 34: 1$ & $22: 22: 29: 1$ & $85 \%$ & 2.7 & 2.3 & 21.1 \\
\hline MP8 & 4900 & 4500 & $23: 23: 68: 1$ & $22: 23: 62: 1$ & $91 \%$ & 2.7 & 2.4 & 42.2 \\
\hline
\end{tabular}

${ }^{*}$ Theoretical values

${ }^{\mathrm{a}}$ Calculated from ${ }^{1} \mathrm{H}$ NMR peak integration of peak a, $\mathrm{d}$ and $\mathrm{j}$

${ }^{\mathrm{b}}$ Calculated from ${ }^{13} \mathrm{C}$ NMR spectra, using Equation (1)

${ }^{\#}$ Conversion $=$ LLA found $/$ in feed

$\mathrm{DMP}=2,2$ dimethyl 1,3 propanediol, the initiator of the PCL-co-PTMC random copolymers 

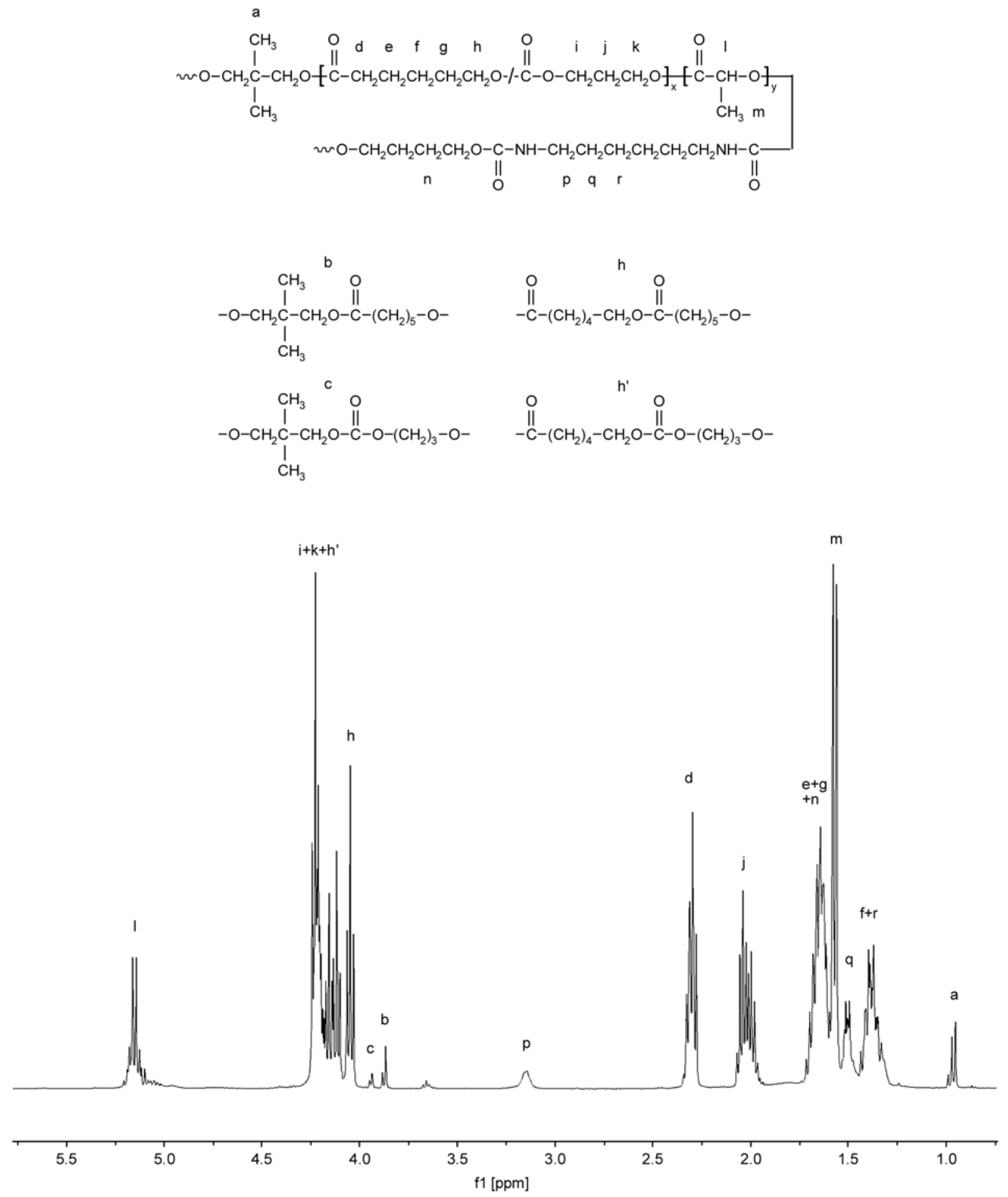

Figure 3. $500 \mathrm{MHz}{ }^{1} \mathrm{H}$ NMR spectrum of MP6 in $\mathrm{CDCl}_{3}$

was attributed to the short uncrystallized HMDIBDO blocks dispersion in the amorphous soft segments matrix [26]. To examine the degree of microphase separation between hard and soft segment, $\Delta T_{\mathrm{g}}$ representing the difference between the $T_{\mathrm{g}}$ of polyurethane due to soft segments (MP1-5) and $T_{\mathrm{g}}$ of macrodiols (SS1-5), was calculated and listed in Table 5. Smaller $\Delta T_{\mathrm{g}}$ reflects decreasing inter-phase interaction and solubilization, that is, increasing phase separation. In other words, polyurethane is well phase-separated if the $\Delta T_{\mathrm{g}}$ is very small [1]. From Table 5, $\Delta T_{\mathrm{g}}$ decreased with increasing $\mathrm{CL}$ molar fraction, suggesting that microphase separation between HS (HMDI-BDO) 


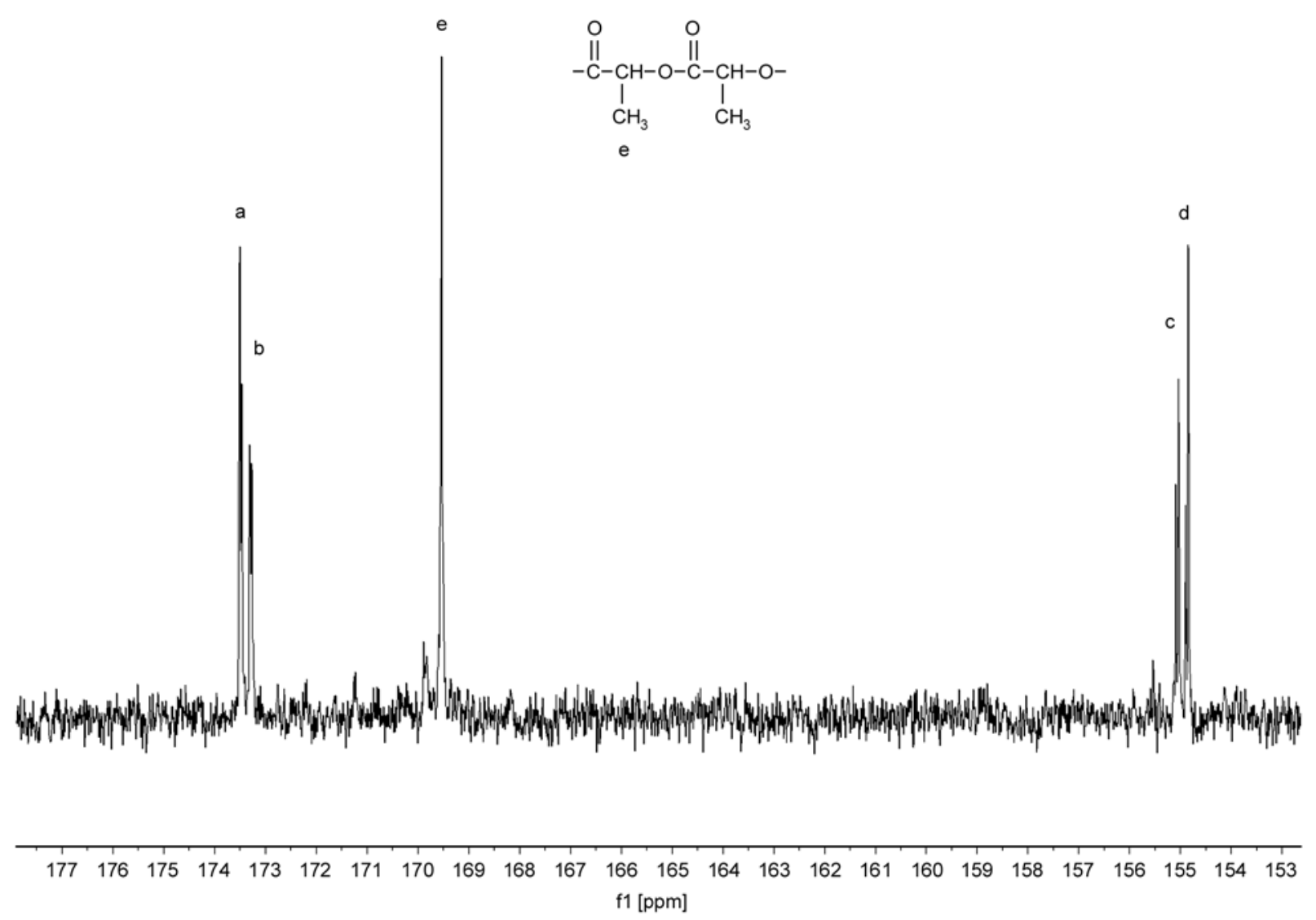

Figure 4. $101 \mathrm{MHz}{ }^{13} \mathrm{C}$ NMR spectrum (carbonyl region) of $\mathrm{MP} 8$ in $\mathrm{CDCl}_{3}$

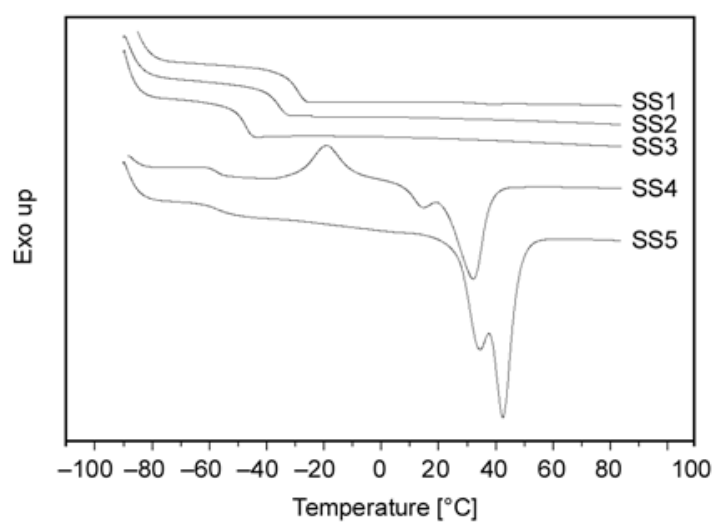

Figure 5. DSC second heating curves of precipitated macrodiols (SS1-5), from -90 to $90^{\circ} \mathrm{C}$. The y-axis was shifted for better clarity

and SS (PCL-co-PTMC) became stronger. This is attributed to the effect of soft segment crystallization that could promote the phase separation, and is comparable to the studies reported on PU based on polycarbonates [27], PEO and PEO-PPO-PEO [28]. In the more extreme case, MP5 with $85 \%$ PCL showed $T_{\mathrm{g}}$ of -53 and $-18^{\circ} \mathrm{C}$, corresponding to PCLrich and PTMC-rich two separated amorphous phases, which was not observed in SS5. The reason

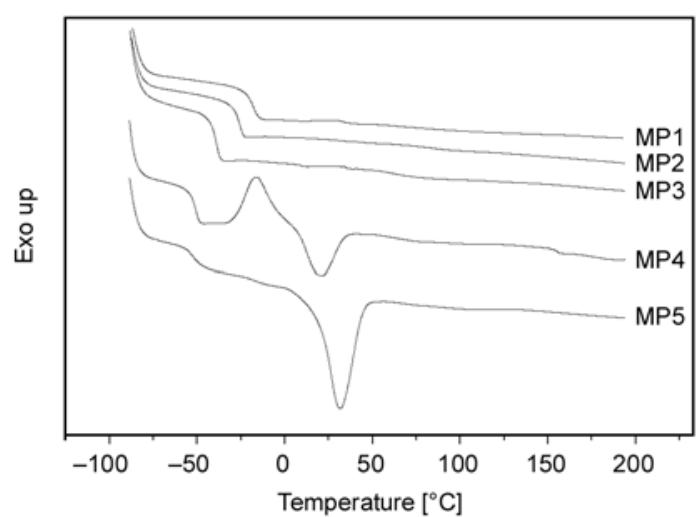

Figure 6. DSC second heating curves of (PCL-co-PTMC) multiblock polyurethane films (MP1-5) from -90 to $200^{\circ} \mathrm{C}$. The $\mathrm{y}$-axis was shifted for better clarity.

of the amorphous phase separation is unclear. It is believed that these short uncrystallized HMDIBDO blocks tend to phase-separate from PCL and phase-mix with PTMC, thus, lead to non-continuous amorphous soft segment matrix. More characterizations such as AFM and DMA are required to further conclude the phase morphology.

Data in Table 5 suggests that crystallization is controlled by CL/TMC molar ratio in the soft seg- 
Table 5. DSC data of the soft segments and (PCL-co-PTMC) multiblock polyurethanes

\begin{tabular}{|c|c|c|c|c|c|c|}
\hline Polymer & $\mathbf{T}_{\mathrm{g}}\left[{ }^{\circ} \mathbf{C}\right]$ & $\mathbf{T}_{\mathrm{c}}\left[{ }^{\circ} \mathbf{C}\right]$ & $\mathbf{T}_{\mathrm{m}}\left[{ }^{\circ} \mathbf{C}\right]$ & $\Delta \mathbf{H}_{\mathbf{f}}[\mathbf{J} / \mathbf{g}]^{\mathbf{a}}$ & $X_{c}[\%]^{d}$ & $\Delta \mathbf{T}_{\mathrm{g}}^{\mathrm{e}}$ \\
\hline SS1 & -29 & - & - & - & - & - \\
\hline SS2 & -36 & - & - & - & - & - \\
\hline SS3 & -47 & - & - & - & - & - \\
\hline SS4 & -57 & $-26^{b},-19^{c}$ & 32 & 58 & 41 & - \\
\hline SS5 & -57 & $2^{b}$ & 42 & 60 & 43 & - \\
\hline MP1 & -18 & - & - & - & - & 11 \\
\hline MP2 & -26 & - & - & - & - & 10 \\
\hline MP3 & -39 & - & - & - & - & 8 \\
\hline MP4 & -51 & $-16^{\mathrm{c}}$ & 20 & 16 & 12 & 6 \\
\hline MP5 & $-53,-18$ & $-14^{\mathrm{b}}$ & 31 & 36 & 26 & 4 \\
\hline
\end{tabular}

The thermal properties of soft segments (SS) and their corresponding multiblock polyurethanes (MP) were included. DSC heating and cooling rate $=20^{\circ} \mathrm{C} / \mathrm{min}$. DSC data were observed from second heating curves, except $T_{\mathrm{c}}$.

${ }^{a}$ Enthalpy of fusion values are per gram of PCL content in the soft segments or multiblock polyurethanes

${ }^{\mathrm{b}}$ Crystallization temperature obtained from cooling curves

${ }^{\mathrm{c} C r y s t a l l i z a t i o n ~ t e m p e r a t u r e ~ o b t a i n e d ~ f r o m ~ s e c o n d ~ h e a t i n g ~ c u r v e ~}$

${ }^{\mathrm{d} D e g r e e}$ of crystallinity based on heat of fusion of $100 \%$ crystalline PCL $=139.5 \mathrm{~J} / \mathrm{g}$

${ }^{\mathrm{e}}$ The difference between $T_{\mathrm{g}}$ of SS and MP

ments. Soft segments crystallization were observed when CL/TMC molar ratio was 75/25 and higher. SS1-3 and MP1-3 did not show any melting transition because of their short average segment lengths ( $L_{\mathrm{CL}}$ of $2.4-4.5$ in Table 3 ). This is in contradiction with PCL-co-PTMC (50/50) copolymers studied by Pêgo et. al. [16]. $L_{\mathrm{CL}}$ of 3.93 was suggested to be long enough to crystallize. In our study, MP1 (15\% PCL) with $L_{\mathrm{CL}}$ of 4.5 was unable to crystallize even though they were long enough, mainly due to the low \%PCL. The degree of crystallization $\left(X_{\mathrm{c}}\right)$ and melting enthalpy of fusion $\left(\Delta H_{\mathrm{f}}\right)$ dropped after chain extension, suggesting smaller, less stable and less organized crystallites were formed in the polyurethanes compared to the macrodiols in Figure 5 [28]. From the DSC analysis showing low degree of phase mixing with PCL, the main restriction of crystallization is due to the reduced chain mobility. MP5 with longer average $L_{\mathrm{CL}}$ of 6.7 was more readily to crystallize after chain extension as compare to MP4 ( $L_{\mathrm{CL}}$ of 4.8 from Table 3 ).

As expected, hard segments transition was not observed in the second heating curves because the amount of HMDI and BDO were as low as $8 \mathrm{wt} \%$. Pure HMDI-BDO hard segment melting transition ranging from $165-182^{\circ} \mathrm{C}$ was reported in previous studies [28-30].

[PLLA-b-(PCL-co-PTMC)-b-PLLA] polyurethanes Figure 7 showed the DSC curves of MP6-8. In Table 6, DSC data of PCL-co-PTMC soft segments, triblocks and their corresponding polyurethanes showed that thermal properties was affected by

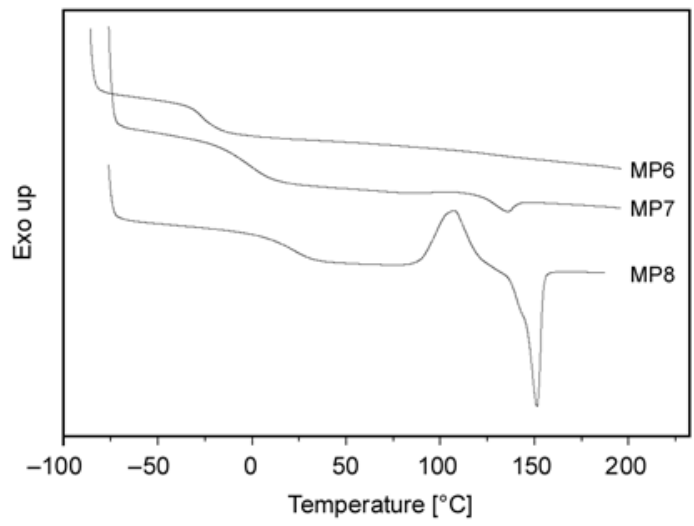

Figure 7. DSC second heating curves of [PLLA-b-(PCLco-PTMC)-b-PLLA] multiblock polyurethane films (MP6-8) from -90 to $200^{\circ} \mathrm{C}$. The $y$-axis was shifted for better clarity.

PLLA block length. Single $T_{\mathrm{g}}$ was observed in the PCL-co-PTMC soft segments, suggesting a continuous amorphous segments. $T_{\mathrm{g}}$ of triblock was increased after incorporation of PLLA blocks due to mixing of amorphous regions from PCL, PTMC and PLLA. The $T_{\mathrm{g}}$ were all below room temperature, suggesting a rubbery amorphous phase. Microphase separation in the second series was assessed by the difference between $T_{\mathrm{g}}$ of TB6-8 and MP6-8 $\left(\Delta T_{\mathrm{g}}\right) . \Delta T_{\mathrm{g}}$ was independent of PLLA block length. This could be attributed to two contrasting phenomena: hydrogen bonding between HMDI-BDO and the carbonyl group from PLLA esters can improve phase mixing; in contrast, crystallization from either segments can enhance phase separation [1].

From data shown in Table 6, the multiblock polyurethane crystallization is controlled by PLLA 
Table 6. DSC data of the soft segments PCL-co-PTMC, triblock copolyesters and [PLLA-b-(PCL-co-PTMC)b-PLLA] multiblock polyurethanes

\begin{tabular}{|l|c|c|c|c|c|c|}
\hline Polymer & $\begin{array}{c}\mathbf{T}_{\mathbf{g}} \\
{\left[{ }^{\circ} \mathbf{C}\right]}\end{array}$ & $\begin{array}{c}\mathbf{T}_{\mathbf{c}} \\
{\left[{ }^{\circ} \mathbf{C}\right]}\end{array}$ & $\begin{array}{c}\mathbf{T}_{\mathbf{m}} \\
{\left[{ }^{\circ} \mathbf{C}\right]}\end{array}$ & $\begin{array}{c}\Delta \mathbf{H}_{\mathbf{f}} \\
{[\mathbf{J} / \mathbf{g}]^{\mathbf{a}}}\end{array}$ & $\begin{array}{c}\mathbf{X}_{\mathbf{c}} \\
{\left[\mathbf{\%}^{\mathbf{b}}\right]^{\mathbf{b}}}\end{array}$ & $\Delta \mathbf{T}_{\mathbf{g}} \mathbf{c}$ \\
\hline SS3 & -47 & - & - & - & - & - \\
\hline SS6 & -49 & - & - & - & - & - \\
\hline SS7 & -47 & - & - & - & - & - \\
\hline SS8 & -47 & - & - & - & - & - \\
\hline TB6 & -32 & - & - & - & - & - \\
\hline TB7 & -10 & 74 & 137 & 39 & 41 & - \\
\hline TB8 & 20 & 82 & 154 & 49 & 53 & - \\
\hline MP3 & -39 & - & - & - & - & 8 \\
\hline MP6 & -27 & - & - & - & - & 5 \\
\hline MP7 & -2 & - & 136 & 5 & 5 & 8 \\
\hline MP8 & 23 & 107 & 152 & 31 & 34 & 3 \\
\hline
\end{tabular}

The thermal properties of soft segments PCL-co-PTMC (SS), triblocks (TB) and their corresponding multiblock polyurethanes (MP) were included. DSC heating rate $=10^{\circ} \mathrm{C} / \mathrm{min}$ and cooling rate $=20^{\circ} \mathrm{C} / \mathrm{min}$. DSC data were observed from second heating curves. SS3 and MP3 data was included for comparison.

${ }^{a}$ Enthalpy of fusion values are per gram of PLLA content in the triblocks or multiblock polyurethanes

${ }^{b}$ Degree of crystallinity based on heat of fusion of $100 \%$ crystalline PLLA $=93 \mathrm{~J} / \mathrm{g}$

${ }^{\mathrm{c}}$ The difference between $T_{\mathrm{g}}$ of TB and MP

block length. Triblock TB6 was found to be a continuous amorphous copolymer with the absence of any melting transition. Semicrystalline triblocks (TB7-8) were observed when the PLLA has average chain length ( $L_{\mathrm{LLA}}$ in Table 4$)$ higher than 21. Melting transition at $137-154^{\circ} \mathrm{C}$ were observed accompanied by high degree of crystallinity. After the addition of HMDI-BDO hard segments, although melting points remained unchanged, the enthalpy (and degree of crystallinity), expecially for MP7, dropped significantly. The decrease in enthalpy is possibly due to the disruption of PLLA crystallinity by the HMDI/BDO. It is not likely that this phenomenon is the result of the change in weight percentage of PLLA, since the enthalpies shown in Table 6 have been normalized.
Similar to series one, hard segments transitions was not observed in the second heating curves obtained from DSC measurement, because it was low in weight percent. With the presence of PLLA crystals, having melting transitions similar to HMDIBDO hard segments, it may replace the role of hard segments as load bearing segments upon deformation.

\subsection{Tensile properties}

\section{(PCL-co-PTMC) polyurethanes}

Table 7 gave a summary of the mechanical properties including the initial modulus, ultimate tensile strength (UTS), the strain-at-break $\left(\varepsilon_{\mathrm{b}}\right)$ and the recovered strain after being stretched to 100 $100-100 \%$ or $100-200-300 \%$ of the initial gage length.

As shown in Figure 8 and Table 7, at room temperature $\left(25^{\circ} \mathrm{C}\right)$, the shape of the stress-strain curves for MP1-5 are typical for lightly crosslinked rubber: smooth transition from elastic to plastic region. MP1-3 showed low UTS which represented soft amorphous materials, which are in agreement with DSC results. MP4 and 5 showed significantly higher moduli, tensile strength, and strain-at-break than

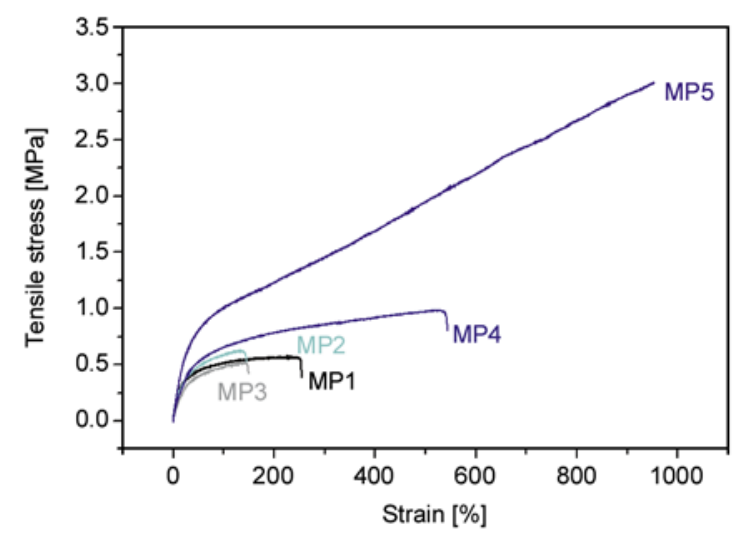

Figure 8. Stress-strain curves of MP1-5 at room temperature $\left(25^{\circ} \mathrm{C}\right)$

Table 7. Tensile measurements and cyclic deformation of (PCL-co-PTMC) multiblock polyurethanes at $25^{\circ} \mathrm{C}$

\begin{tabular}{|c|c|c|c|c|c|c|c|}
\hline Multiblock PU (MP) & $\begin{array}{c}\text { CL/TMC } \\
{[\mathrm{mol} \%]}\end{array}$ & $\begin{array}{c}\text { Initial modulus } \\
{[\mathrm{MPa}]}\end{array}$ & $\begin{array}{c}\text { UTS } \\
\text { [MPa] }\end{array}$ & $\begin{array}{c}\varepsilon_{\mathrm{b}} \\
{[\%]}\end{array}$ & $\begin{array}{c}\varepsilon_{R 1} \\
{[\% / 100 \%]}\end{array}$ & $\begin{array}{c}\varepsilon_{R 2} \\
{[\% / 100 \%]}\end{array}$ & $\begin{array}{c}\varepsilon_{\mathrm{R} 3} \\
{[\% / 100 \%]}\end{array}$ \\
\hline MP1 & $15 / 85$ & $3.2 \pm 0.8$ & $0.51 \pm 0.11$ & $246 \pm 6$ & 77 & 74 & 70 \\
\hline MP2 & $25 / 75$ & $3.6 \pm 0.8$ & $0.63 \pm 0.05$ & $133 \pm 13$ & 79 & 75 & 73 \\
\hline MP3 & $50 / 50$ & $2.2 \pm 0.3$ & $0.51 \pm 0.06$ & $133 \pm 20$ & 81 & 79 & 75 \\
\hline MP4 & $75 / 25$ & $2.6 \pm 0.2$ & $1.00 \pm 0.13$ & $519 \pm 85$ & 87 & $83^{\mathrm{a}}$ & $76^{\mathrm{b}}$ \\
\hline MP5 & $85 / 15$ & $3.6 \pm 0.2$ & $2.98 \pm 0.09$ & $954^{\mathrm{c}}$ & 75 & $57^{\mathrm{a}}$ & $49^{b}$ \\
\hline
\end{tabular}

Tensile test was conducted with number of sample $n=3-7$ in each multiblock polyurethane

an second cycle, sample was deformed to $200 \%$, strain recovery is $\%$ recovered $/ 200 \%$

${ }^{b}$ In third cycle, sample was deformed to $300 \%$, strain recovery is \%recovered $/ 300 \%$

${ }^{\mathrm{c}}$ Testing samples $(n=3)$ were not failed after machine limit, the standard deviation is not applicable 
MP1-3, as a result of crystallizable PCL segments. MP1-5 showed UTS lower than traditional PU as the hard segment content was low and it did not crystallize. Their UTS and breaking strain were proportional to the degree of crystallinity. This is agreeable with the study conducted by Skarja [11]. The presence of PCL crystals was anticipated to act as physical network in a way that similar to hard segments [11]. They may absorb deformation energy through unfolding some of the isotropic crystalline lamellar and form new strain-induced crystalline lamellar perpendicular to the strain direction [31]. In Figure 8, MP5 showed the best tensile properties with PCL-co-PTMC 85/15 composition. It showed a dramatic increase in UTS and strain at break when compared to MP4 because MP5 has a relatively higher degree of crystallinity and melting point. Strain-induced crystallization in MP5 is extensive since its $T_{\mathrm{m}}\left(31^{\circ} \mathrm{C}\right)$ is close to room temperature thus mobility of the chain is high. However, MP4 has $T_{\mathrm{m}}$ slightly lower than room temperature. The crystalline region would have partially molten before it could be strain-crystallized.

[PLLA-b-(PCL-co-PTMC)-b-PLLA] polyurethanes Second series of polyurethane elastomers with different PLLA block length were studied. Table 8 compared the tensile properties with MP3. Without PLLA blocks, MP3 showed low UTS and initial modulus that represented weak and soft materials. Polyurethanes based on triblock [PLLA-b-(PCLco-PTMC)-b-PLLA] copolymers presented tougher and stronger behavior. At room temperature $\left(25^{\circ} \mathrm{C}\right)$, the UTS and initial moduli increased proportional to the PLLA block length. This result is coherent with the mechanical tests of PLA-PTMC-PLA copolyesters reported by Zhang et al. [32].

In Figure 9, MP8 showed the highest initial modulus and UTS among all the polyurethanes in this study. In contrast, completely amorphous polyurethanes including MP6 and MP1-3 in this study showed limited elongation, low UTS and initial moduli. These can be attributed several factors that played significant role in the tensile properties of polyurethane. First, PCL or PLLA with moderate degree of crystallinity acts as reinforment filler to absorb deformation energy [12]. As noted in NMR and DSC measurement, PCL or PLLA segments crystallized in polyurethanes MP4, MP5, MP7 and MP8. Secondly, although all the HMDI-BDO segments of the multiblock polyurethanes were not crystalline, PLLA in the soft segments had high melting points which acted as additional hard seg-

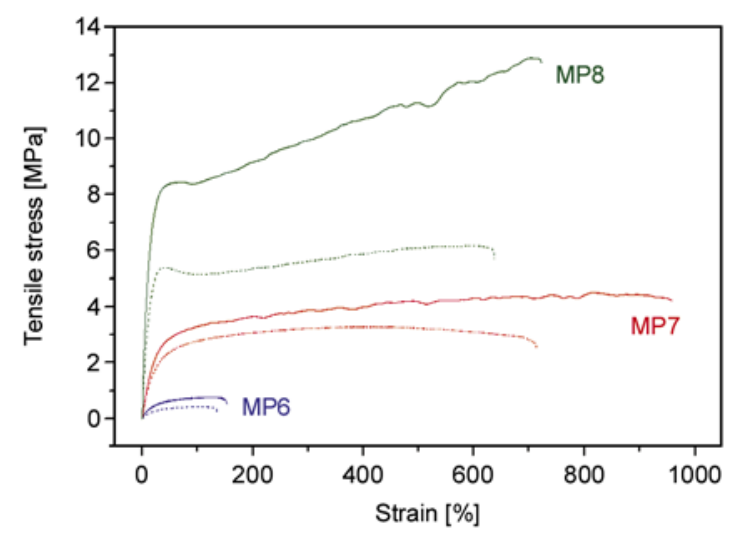

Figure 9. Stress-strain curves of MP6-8 at both room temperature (solid line) and body temperature (dotted line)

Table 8. Tensile test data of [PLLA-b-(PCL-co-PTMC)-b-PLLA] multiblock polyurethanes at room temperature and body temperature

\begin{tabular}{|c|c|c|c|c|c|}
\hline Multiblock PU (MP) & $\begin{array}{c}\text { PLLA block } M_{n} \\
{\text { [Da }{ }^{*}}^{*}\end{array}$ & $\begin{array}{c}\text { Initial Modulus } \\
{[\mathrm{MPa}]}\end{array}$ & $\begin{array}{c}\text { UTS } \\
{[\mathrm{MPa}]}\end{array}$ & $\begin{array}{c}\varepsilon_{\mathbf{b}} \\
{[\%]}\end{array}$ & $\begin{array}{c}\varepsilon_{\mathrm{R} 1} \\
{[\% / 100 \%]}\end{array}$ \\
\hline \multicolumn{6}{|c|}{$25^{\circ} \mathrm{C}$} \\
\hline MP3 & 0 & $2.2 \pm 0.3$ & $0.51 \pm 0.06$ & $133 \pm 20$ & 81 \\
\hline MP6 & 1000 & $3.6 \pm 0.4$ & $0.65 \pm 0.10$ & $116 \pm 14$ & 88 \\
\hline MP7 & 2500 & $16.3 \pm 1.6$ & $4.58 \pm 0.07$ & $919^{a}$ & 93 \\
\hline MP8 & 5000 & $65.4 \pm 17.7^{\wedge}$ & $12.90^{\wedge}$ & $723^{\wedge}$ & 79 \\
\hline \multicolumn{6}{|c|}{$37^{\circ} \mathrm{C}$} \\
\hline MP6 & 1000 & $2.8 \pm 0.2$ & $0.49 \pm 0.06$ & $126 \pm 14$ & 88 \\
\hline MP7 & 2500 & $13.4 \pm 0.2$ & $3.28 \pm 0.05$ & $582 \pm 187$ & 87 \\
\hline MP8 & 5000 & $52.1 \pm 1.8^{\wedge}$ & $6.17^{\wedge}$ & $637^{\wedge}$ & 80 \\
\hline
\end{tabular}

Tensile test was conducted with number of sample $n=2-3$ in each multiblock polyurethane

${ }^{*}$ Theoretical value

aTesting samples $(n=3)$, one of them was not failed after machine limit, the standard deviation is not applicable

${ }^{\wedge}$ Test was not triplicated due to films imperfection 
ments. Lastly, MP6 and MP1-3 polyurethanes showed relatively low molar masses, and thus lowered tensile properties.

\subsection{Temperature effect on tensile properties}

Polyurethanes in the first series were unable to sustain deformation at body temperature $\left(37^{\circ} \mathrm{C}\right)$. They became soft and too weak to be tested mechanically. The PU lost its structural integrity due to lack of hard segment crystallization to act as additional physical crosslinks at higher temperature.

Table 8 and Figure 9 showed that tensile properties of polyurethanes in the second series were temperature dependent. As temperature increased, UTS, initial modulus and strain-at-break decreased slightly. Unlike PCL crystals in the first series, PLLA crystals exhibited higher melting point that would not melt away at body temperature. Instead, the decrease in tensile properties is possibly due to the differences between $T_{\mathrm{g}}$ and testing temperature, especially for MP8 with $T_{\mathrm{g}}$ at $23^{\circ} \mathrm{C}$. At room temperature $\left(25^{\circ} \mathrm{C}\right)$, strain-induced crystallization was extensive, leading to high elongation. At body temperature, further away from its $T_{\mathrm{g}}$, polymer chains gained higher mobility that allowed phase mixing between esters in the soft segments and urethanes in the hard segments [1].

\subsection{Tensile cyclic hysteresis and strain recovery}

As discussed in previous section, tensile strength and initial modulus of polyurethanes depend on structural rigidity that results from soft segments crystallinity, as the HMDI-BDO hard segments did not crystallize. MP8 showed the highest tensile strength and initial modulus. In contrast, stress hysteresis and strain recovery depend more on domain ductility and restructuring [1]. From our tensile cyclic test results, although MP8 showed the best tensile properties, it did not exhibit the highest strain recovery.

Table 7 showed the trend of strain recovery of the multiblock PU after tensile cyclic tests. In MP1-4, the $\%$ of strain being recovered was proportional to the $\% \mathrm{PCL}$ in the random copolymer, except that MP5 demonstrated slightly lower strain recovery. The optimum CL/TMC composition to achieve highest strain recovery lies between $75 / 25$ to $85 / 15$, with moderate PCL crystallinity $\left(X_{\mathrm{c}}\right)$ between 12 $26 \%$ (refer to Table 5). In Table 8 , strain recovery

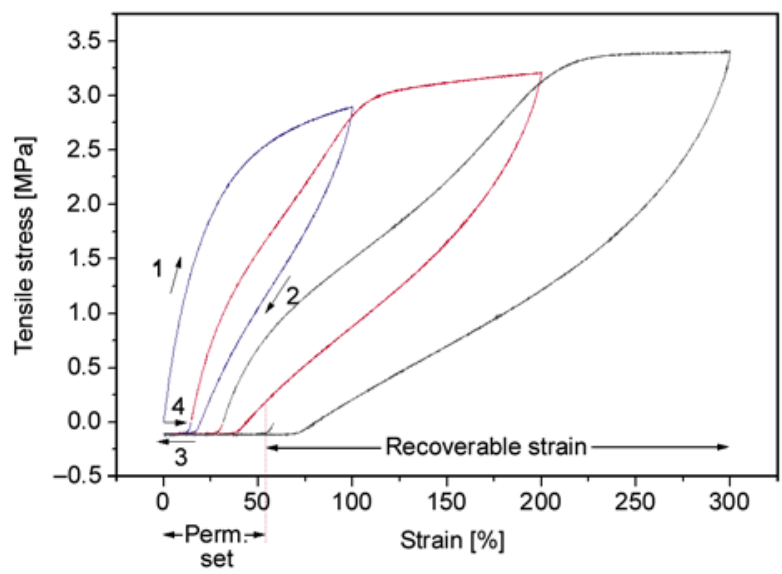

Figure 10. Tensile stress hysteresis of MP7 at $37^{\circ} \mathrm{C}$, programming to $100-200-300 \%$ tensile cyclic loading-unloading

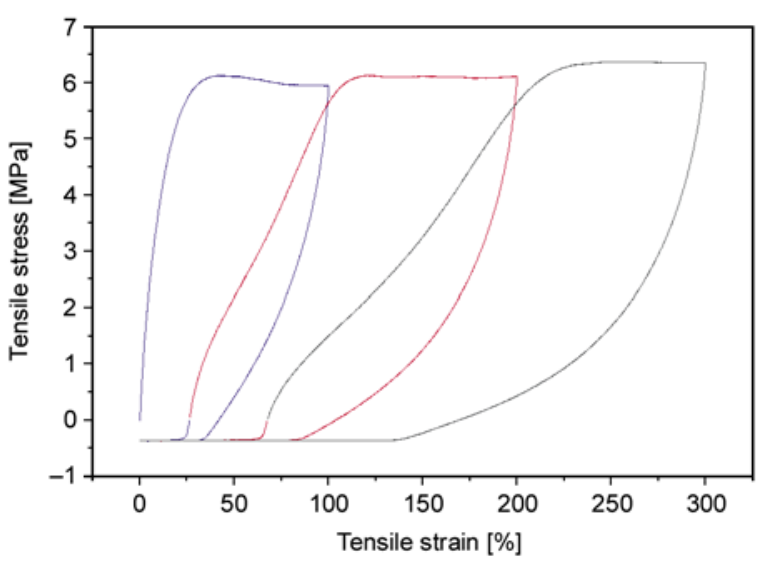

Figure 11. Tensile stress hysteresis of MP8 at $37^{\circ} \mathrm{C}$, programming to $100-200-300 \%$ tensile cyclic loading-unloading

of MP6-8 with PLLA blocks were compared to MP3. It appears that the recoverable strain after $100 \%$ elongation was related to the PLLA block length. MP7 with low PLLA crystallinity (5\%) showed the highest strain recovery of $93 \%$ in one minute. Similar to MP5 in the first series, MP8 in series two was not following the trend. It exhibited a slight drop in strain recovery, indicating the optimum PLLA crystallinity stayed between 5-34 \%. These phenomena were attributed to PCL or PLLA crystallinity that impeded proper stress transfer to the continuous phase [12] and thus hindered domain restructuring. Moreover, their strain recoveries were barely affected by temperature, as shown in Table 8, because of the high PLLA melting point. Figures 10 and 11 depicted the cyclic tensile 100$200-300 \%$ of MP7 and MP8, respectively. MP7 exhibited strain recovery pattern that is smooth with 
smaller hysteresis compared to MP8. More permanent set was evident in MP8 that showed yield point in the stress-strain curves (Figure 9).

\section{Conclusions}

The two sets of multiblock thermoplastic polyurethane elastomers reported in this study were different from previous studies in that the optimization of mechanical properties was studied by (i) crystallization of PCL in PCL-co-PTMC soft segments and (ii) crystallization of PLLA in PLLA-b-(PCLco-PTMC)-b-PLLA triblock soft segments. First, the (PCL-co-PTMC) polyurethanes were synthesized and characterized. With low hard segment content, hard segment crystallinity was hardly observed. Increasing the PCL/PTMC molar ratio in the soft segments was found to have lowered the $T_{\mathrm{g}}$, increased molar mass, and soft segments crystallinity. Mechanically, completely amorphous soft segments were shown to yield multiblock PUs which were soft and weak. The presence of moderate PCL crystallinity improved the tensile strength, initial modulus and strain-at-break while relatively low PCL crystallinity yielded the highest strain recovery. However, tensile properties of (PCL-coPTMC) polyurethanes were greatly affected when being tested at body temperature due to the melting of PCL crystals. To solve this problem, 'pseudo hard segments' represented by PLLA blocks were introduced in the polyurethanes. When the (PCLco-PTMC) polyurethanes were compared with [PLLA-b-(PCL-co-PTMC)-b-PLLA] polyurethanes, the presence of PLLA blocks significantly improved the tensile properties. PLLA soft segments with high melting point allowed the formation of additional physical crosslink points that can sustain deformation at body temperature, in addition to reducing potential toxicity due to high diisocyanate content. Similar to PCL crystals, the presence of moderate PLLA crystallinity improved the tensile strength and initial modulus while the highest strain recovery was achieved at low PLLA crystallinity. These polyurethanes are attractive as biomaterials for dynamic environment that demands high elasticity such as tissue engineering scaffolds and interventional cardiovascular devices, due to their excellent strain recovery and tensile properties at body temperature. Their thermal and mechanical properties are easily tunable by soft segment crystallinity.

\section{Acknowledgements}

This study was financially supported by Ministry of Education (MOE) Singapore. The authors are grateful to Dr. J. Kohn and Dr. D. Bolikal in New Jersey Center for Biomaterials (NJCBM), United States, for their advice and support in this study.

\section{References}

[1] Lamba N. M. K., Woodhouse K. A., Cooper S. L.: Polyurethanes in biomedical applications. CRC Press, Boca Raton (1998).

[2] Tuominen J., Kylmä J., Kapanen A., Venelampi O., Itävaara M., Seppälä J.: Biodegradation of lactic acid based polymers under controlled composting conditions and evaluation of the ecotoxicological impact. Biomacromolecules, 3, 445-455 (2002).

DOI: $10.1021 / \mathrm{bm} 0101522$

[3] Guelcher S. A.: Biodegradable polyurethanes: Synthesis and applications in regenerative medicine. Tissue Engineering Part B: Reviews, 14, 3-17 (2008). DOI: $10.1089 /$ teb.2007.0133

[4] Guan J., Sacks M. S., Beckman E. J., Wagner W. R.: Synthesis, characterization, and cytocompatibility of elastomeric, biodegradable poly(ester-urethane)ureas based on poly(caprolactone) and putrescine. Journal of Biomedical Materials Research, 61, $493-503$ (2002). DOI: $10.1002 / \mathrm{jbm} .10204$

[5] Hassan M. K., Mauritz K. A., Storey R. F., Wiggins J. S.: Biodegradable aliphatic thermoplastic polyurethane based on poly( $\varepsilon$-caprolactone) and L-lysine diisocyanate. Journal of Polymer Science Part A: Polymer Chemistry, 44, 2990-3000 (2006).

DOI: $10.1002 /$ pola.21373

[6] Kylmä J., Seppälä J. V.: Synthesis and characterization of a biodegradable thermoplastic poly(ester-urethane) elastomer. Macromolecules, 30, 2876-2882 (1997). DOI: $10.1021 / \mathrm{ma9} 61569 \mathrm{~g}$

[7] Ryynänen T., Nykännen A., Seppälä J. V.: Poly(CL/ DLLA-b-CL) multiblock copolymers as biodegradable thermoplastic elastomers. Express Polymer Letters, 2, 184-193 (2008). DOI: 10.3144 /expresspolymlett.2008.23

[8] Guan J., Sacks M. S., Beckman E. J., Wagner W. R.: Biodegradable poly(ether ester urethane)urea elastomers based on poly(ether ester) triblock copolymers and putrescine: Synthesis, characterization and cytocompatibility. Biomaterials, 25, 85-96 (2004).

DOI: 10.1016/S0142-9612(03)00476-9

[9] Hong Y., Guan J., Fujimoto K. L., Hashizume R., Pelinescu A. L., Wagner W. R.: Tailoring the degradation kinetics of poly(ester carbonate urethane)urea thermoplastic elastomers for tissue engineering scaffolds. Biomaterials, 31, 4249-4258 (2010). DOI: $10.1016 /$ j.biomaterials.2010.02.005

[10] Asplund J. O. B., Bowden T., Mathisen T., Hilborn J.: Synthesis of highly elastic biodegradable poly(urethane urea). Biomacromolecules, 8, 905-911 (2007). DOI: $\underline{10.1021 / \mathrm{bm} 061058 \mathrm{u}}$ 
[11] Skarja G. A.: The development and characterization of degradable, segmented polyurethanes containing amino acid-based chain extenders. PhD thesis, University of Toronto (2001).

[12] Waletzko R. S., Korley L. T. J., Pate B. D., Thomas E. L., Hammond P. T.: Role of increased crystallinity in deformation-induced structure of segmented thermoplastic polyurethane elastomers with PEO and PEOPPO-PEO soft segments and HDI hard segments. Macromolecules, 42, 2041-2053 (2009). DOI: $10.1021 / \mathrm{ma} 8022052$

[13] Albertsson A-C., Eklund M.: Synthesis of copolymers of 1,3-dioxan-2-one and oxepan-2-one using coordination catalysts. Journal of Polymer Science Part A: Polymer Chemistry, 32, 265-279 (1994).

DOI: $10.1002 /$ pola.1994.080320207

[14] Domb A. J., Kumar N., Sheskin T., Bentolila A., Slager J., Teomim D.: Biodegradable polymers as drug carrier systems. in 'Polymeric biomaterials' (ed.: Dumitriu S.) Marcel Dekker, New York, 91-122 (2002).

[15] Kricheldorf H. R., Rost S.: Biodegradable multiblock copolyesters prepared from $\varepsilon$-caprolactone, L-lactide, and trimethylene carbonate by means of bismuth hexanoate. Macromolecules, 38, 8220-8226 (2005). DOI: $10.1021 / \mathrm{ma} 050439 \mathrm{~h}$

[16] Pêgo A. P., Zhong Z., Dijkstra P. J., Grijpma D. W., Feijen J.: Influence of catalyst and polymerization conditions on the properties of 1,3-trimethylene carbonate and $\varepsilon$-caprolactone copolymers. Macromolecular Chemistry and Physics, 204, 747-754 (2003). DOI: $10.1002 /$ macp. 200390043

[17] Shen Y., Shen Z., Zhang Y., Yao K.: Novel rare earth catalysts for the living polymerization and block copolymerization of $\varepsilon$-caprolactone. Macromolecules, 29, 8289-8295 (1996).

DOI: $10.1021 / \mathrm{ma} 9518060$

[18] Shen Y., Shen Z., Zhang Y., Huang Q., Shen L., Yuan H.: Random copolymerization of $\varepsilon$-caprolactone and trimethylene carbonate with rare earth catalysts. Journal of Applied Polymer Science, 64, 2131-2139 (1997).

DOI: $10.1002 /($ SICI) 1097-4628(19970613)64:11<2131 $\because$ AID-APP9>3.0.CO;2-K

[19] Crescenzi V., Manzini G., Calzolari G., Borri C.: Thermodynamics of fusion of poly- $\beta$-propiolactone and poly-e-caprolactone. Comparative analysis of the melting of aliphatic polylactone and polyester chains. European Polymer Journal, 8, 449-463 (1972).

DOI: 10.1016/0014-3057(72)90109-7

[20] Fischer E. W., Sterzel H. J., Wegner G.: Investigation of the structure of solution grown crystals of lactide copolymers by means of chemical reactions. Colloid and Polymer Science, 251, 980-990 (1973). DOI: $10.1007 / \mathrm{BF} 01498927$

[21] Lipik V. T., Kong J. F., Chattopadhyay S., Widjaja L. K., Liow S. S., Venkatraman S. S., Abadie M. J. M.: Thermoplastic biodegradable elastomers based on $\varepsilon$-caprolactone and L-lactide block co-polymers: A new synthetic approach. Acta Biomaterialia, 6, 4261-4270 (2010). DOI: $10.1016 /$ j.actbio.2010.05.027
[22] Liow S. S., Widjaja L. K., Lipik V. T., Abadie M. J. M.: Synthesis, characterization and photopolymerization of vinyl functionalized poly ( $\varepsilon$-caprolactone). Express Polymer Letters, 3, 159-167 (2009).

DOI: 10.3144 /expresspolymlett.2009.21

[23] Dubois P., Jérôme R., Teyssié P.: Macromolecular engineering of polylactones and polylactides. 3 . Synthesis, characterization, and applications of poly(i\&-caprolactone) macromonomers) macromonomers. Macromolecules, 24, 977-981 (1991).

DOI: $10.1021 / \mathrm{ma} 00005 \mathrm{a} 002$

[24] Kowalski A., Duda A., Penczek S.: Kinetics and mechanism of cyclic esters polymerization initiated with tin(II) octoate, 1. Polymerization of $\varepsilon$-caprolactone. Macromolecular Rapid Communications, 19, 567-572 (1998).

DOI: 10.1002/(SICI)1521-3927(19981101)19:11<567 ::AID-MARC567>3.0.CO;2-T

[25] Kricheldorf H. R., Kreiser-Saunders I., Stricker A.: Polylactones 48. SnOct 2 -initiated polymerizations of lactide: A mechanistic study. Macromolecules, 33, 702-709 (2000).

DOI: $10.1021 / \mathrm{ma99} 1181 \mathrm{w}$

[26] Drobny J. G.: Handbook of thermoplastic elastomers. William Andrew Publishing, New York (2007).

[27] Kojio K., Furukawa M., Motokucho S., Shimada M., Sakai M.: Structure-mechanical property relationships for poly(carbonate urethane) elastomers with novel soft segments. Macromolecules, 42, 8322-8327 (2009). DOI: $10.1021 / \mathrm{ma901317t}$

[28] Korley L. T. J., Pate B. D., Thomas E. L., Hammond P. T.: Effect of the degree of soft and hard segment ordering on the morphology and mechanical behavior of semicrystalline segmented polyurethanes. Polymer, 47, 3073-3082 (2006).

DOI: 10.1016/j.polymer.2006.02.093

[29] Li Y., Ren Z., Zhao M., Yang H., Chu B.: Multiphase structure of segmented polyurethanes: Effects of hardsegment flexibility. Macromolecules, 26, 612-622 (1993). DOI: $10.1021 / \mathrm{ma} 00056 \mathrm{a} 010$

[30] Kajiyama T., MacKnight W. J.: Thermal properties of polyurethanes. Enthalpies and entropies of fusion. Polymer Journal, 1, 548-554 (1970).

[31] Toki S., Sics I., Burger C., Fang D., Liu L., Hsiao B. S., Datta S., Tsou A. H.: Structure evolution during cyclic deformation of an elastic propylene-based ethylene-propylene copolymer. Macromolecules, 39, 3588-3597 (2006).

DOI: $10.1021 / \mathrm{ma} 0600106$

[32] Zhang Z., Grijpma D. W., Feijen J.: Triblock copolymers based on 1,3-trimethylene carbonate and lactide as biodegradable thermoplastic elastomers. Macromolecular Chemistry and Physics, 205, 867-875 (2004). DOI: $10.1002 / \mathrm{macp} .200300184$ 